\title{
Semi-quantitative analysis of Ruminococcus flavefaciens, Fibrobacter succinogenes and Streptococcus bovis in the equine large intestine using real-time polymerase chain reaction
}

\author{
Peter M. Hastie ${ }^{1 *}$, Katherine Mitchell ${ }^{2}$ and Jo-Anne M. D. Murray ${ }^{2}$ \\ ${ }^{1}$ Division of Veterinary Cell Sciences, Institute of Comparative Medicine, University of Glasgow Veterinary School, \\ Bearsden Road, Glasgow G61 1QH, UK \\ ${ }^{2}$ Division of Veterinary Clinical Sciences, Royal (Dick) School of Veterinary Studies, University of Edinburgh, \\ Easter Bush, Roslin, Midlothian EH25 9RG, UK
}

(Received 5 July 2007 - Revised 10 December 2007 - Accepted 11 December 2007 - First published online 1 April 2008)

There is a need to further our understanding of the role that the equine hindgut ecosystem plays in digestive processes and diseases. The aim of the present study was to utilise the real-time PCR technique to determine the abundance of candidate cellulolytic (Ruminococcus flavefaciens; Fibrobacter succinogenes) and non-cellulolytic (Streptococcus bovis) bacteria in lumen contents from the caecum, ventral and dorsal colon, and rectum of healthy horses $\left(n\right.$ 14). Total DNA was extracted from frozen and lyophilised lumen contents, and PCR primers and Taqman ${ }^{\circledR}$ probes were designed based on 16S rDNA sequences for specific detection of candidate bacterial species. Overall, in frozen and lyophilised digesta, there were significantly $(P<0.01)$ fewer candidate bacteria in the caecum than the dorsal colon and rectum. In frozen digesta, candidate bacteria levels were similar between the ventral colon, dorsal colon and rectum, but in lyophilised digesta there were significantly $(P<0.05)$ higher levels of bacteria in the dorsal colon and rectum. Frozen digesta contained disparate levels of candidate bacteria such that $R$. flavefaciens $>$ $F$. succinogenes $>S$. bovis $(P<0.05)$, while in lyophilised digesta $R$. flavefaciens was present in significantly $(P<0.05)$ greater amounts than $F$. succinogenes and $S$. bovis. R. flavefaciens and $F$. succinogenes were abundant at significantly $(P<0.05)$ greater levels in lyophilised digesta $v$. frozen digesta, with no difference in $S$. bovis levels. These data indicate that for these bacteria at least, faeces are a suitable model for studying the bacterial ecosystem within the equine colon. The present study also indicates that the preservation method of digesta affects levels of bacteria detected.

Horses: Intestine: Bacteria: Real-time polymerase chain reaction

Horses have evolved from ancestors with an intestinal system designed to process large quantities of low-quality forage, containing high levels of structural plant polysaccharides, ingested on an almost continuous basis to meet their nutrient demands. The large intestine (hindgut) of the horse is anatomically specialised to accommodate microorganisms capable of degrading and fermenting structural polysaccharides of the plant cell wall, which are generally resistant to pre-caecal digestion ${ }^{(1)}$. The fermentation of feedstuffs in the hindgut results in the production of volatile fatty acids that, when absorbed, constitute a significant proportion $(30 \%)$ of the digestible energy intake of the animal; particularly in horses fed high-fibre diets ${ }^{(2)}$. Fibrebased diets are known to maintain normal fermentation conditions within the large intestine whilst, in contrast, diets containing high levels of concentrates (starch) can be detrimental to the maintenance of a homeostatic hindgut environment ${ }^{(3)}$, and can lead to a number of metabolic disorders such as acidosis and laminitis ${ }^{(4-7)}$.
Despite the importance of the intestinal microbial ecosystem in many aspects of host animal health and performance in other species, particularly ruminants, there is a dearth of information regarding the microbial ecology of the equine hindgut. A greater understanding of the microbial diversity of the hindgut is essential for improving our knowledge of digestive processes, and for the future prevention and treatment of diseases involving the gastrointestinal tract, for example, laminitis and grass sickness. However, knowledge of the bacterial populations present in the large intestine of the horse is very limited, compared, for example, with the rumen $^{(8)}$ and the caecum and colon of humans and pigs ${ }^{(9,10)}$. Current knowledge of gut microbial ecology and diversity is almost exclusively based on the use of classic culture-based methods that are often laborious, time consuming and may only recover a fraction of the microbial diversity present within the gut $^{(11)}$. However, advanced modern molecular methods, such as real-time semi-quantitative PCR (Q-PCR), are culture-independent tools for accurate and sensitive

Abbreviations: $\mathrm{C}_{\mathrm{T}}$, cycle threshold; Q-PCR, semi-quantitative PCR.

* Corresponding author: Dr Peter M. Hastie, fax +44 141330 5797, email P.Hastie@vet.gla.ac.uk 
quantification of individual bacterial species as well as total bacterial numbers ${ }^{(12,13)}$. Limited studies have reported the bacterial diversity within the large intestine of the horse using more conventional molecular methods such as endpoint PCR or use of oligonucleotides ${ }^{(11,14,15)}$, with these studies identifying the fibrolytic bacteria Ruminococcus flavefaciens and Fibrobacter succinogenes predominating. In these early hybridisation studies investigating the equine hindgut, some authors have lyophilised the material in order to account for the DM increase along the intestinal tract ${ }^{(14)}$, whilst others have extracted DNA from frozen material ${ }^{(11,15)}$. However, it is unclear if the preservation method affects the data obtained from studies using PCR methodologies and whether this should be considered when interpreting results from frozen and lyophilised material.

Furthermore, to our knowledge, there are no published data on the identification or quantification of equine intestinal bacteria using real-time PCR technology, which is a more accurate and sensitive alternative to conventional end-point PCR-based methodologies, and has recently been applied to study diet-dependent shifts in the bacterial populations of the rumen ${ }^{(16)}$ and infant gut ${ }^{(17)}$. Moreover, previous studies investigating microbial diversity and fermentation characteristics within the equine hindgut typically used animals specifically euthanased for the purpose, or surgically modified animals. Whilst these methods have provided important insights into the equine microbial ecosystem, they can be expensive and there is a consensus nowadays to adopt, where possible, cost-effective welfare-friendly alternatives.

Consequently, the objectives of the work reported here were to: (1) optimise real-time Q-PCR methodologies for quantifying changes in relative amounts of $R$. flavefaciens, $F$. succinogenes (fibrolytic bacteria) and Streptococcus bovis (non-fibrolytic bacterium) in the luminal contents of the equine caecum, ventral colon, dorsal colon and rectum; (2) compare the relative amounts of these candidate bacteria in frozen and lyophilised samples; (3) establish whether faeces are a suitable model of hindgut function in the horse. The candidate bacteria are likely to play key roles in equine digestion and health, given that $F$. succinogenes and $R$. flavefaciens are key fibrolytic bacteria, whilst the saccharolytic bacterium $S$. bovis has been proposed as having a role in hindgut acidosis and laminitis ${ }^{(7,14,18)}$.

\section{Materials and methods}

\section{Collection and processing of samples}

Samples of luminal contents (caecum; ventral colon; dorsal colon; rectum) were taken from fourteen freshly slaughtered horses (unknown age and breed), not suffering from any known intestinal diseases, obtained from the local abattoir. Upon recovery, lumen contents were placed in individually labelled grip-top bags and immediately placed on dry ice. At the laboratory, each sample was sub-divided into two groups; one of which remained frozen and was stored at $-80^{\circ} \mathrm{C}$ until required, whilst the other was lyophilised to constant weight before storage at $-80^{\circ} \mathrm{C}$. Quantification was carried out in luminal contents only, as previous work has established that microbial community structure between the hindgut wall and lumen contents is not different in equines ${ }^{(11)}$.

\section{DNA extraction}

Total DNA extraction from frozen and lyophilised luminal samples was carried out using the QIAamp ${ }^{\circledR}$ DNA stool kit (Qiagen Ltd, Crawley, West Sussex, UK). This purifies genomic, bacterial, viral and parasite DNA from stool samples and was used in accordance with the manufacturer's recommendations, with some modifications. The following procedure was carried out for each sample of frozen and lyophilised lumen contents.

Lumen contents (180-220 mg) were homogenised in $1.4 \mathrm{ml}$ of buffer ASL using a RiboLyser (Hybaid Ltd, Ashford, Middlesex, UK). Following homogenisation each sample was heated at $95^{\circ} \mathrm{C}$ for $5 \mathrm{~min}$ to lyse the bacteria, and then centrifuged for $3 \mathrm{~min}$ at $14000 \mathrm{~g}$. The supernatant fraction was removed and placed into a microcentrifuge tube where it was vortexed with an InhibitEX tablet for $1 \mathrm{~min}$, or until the tablet was completely suspended. The suspension was then incubated for $1 \mathrm{~min}$ at room temperature to allow potential PCR inhibitors or DNA-degrading substances to absorb to the InhibitEX matrix. The InhibitEX reagent was then pelleted by centrifugation for $3 \mathrm{~min}$ at $14000 \mathrm{~g}$, after which $200 \mu \mathrm{l}$ of the supernatant fraction was then removed and placed in a new microcentrifuge tube containing $15 \mu$ l proteinase $\mathrm{K}$. Then $200 \mu l$ buffer AL was added and the mixture was thoroughly vortexed for $15 \mathrm{~s}$. After further heating at $70^{\circ} \mathrm{C}$ for $10 \mathrm{~min}$ to allow protein digestion and degradation under denaturing conditions, $200 \mu \mathrm{l}$ absolute ethanol was added. The resultant mixture was then loaded onto a QIAamp ${ }^{\circledR}$ spin column (Qiagen Ltd) and centrifuged for $3 \mathrm{~min}$ at $14000 \mathrm{~g}$. The DNA bound to the spin column was then washed in two centrifugation steps, first with $500 \mu \mathrm{l}$ of buffer AW1 followed by $500 \mu \mathrm{l}$ buffer AW2, at $14000 \mathrm{~g}$ for $1 \mathrm{~min}$ and $3 \mathrm{~min}$, respectively. Finally, purified DNA was eluted from the spin column in $200 \mu \mathrm{l}$ of buffer AE by allowing it to incubate for $1 \mathrm{~min}$ at room temperature, followed by centrifugation at $14000 \mathrm{~g}$ for $1 \mathrm{~min}$. DNA was stored at $-20^{\circ} \mathrm{C}$ until required for realtime PCR.

\section{Real-time polymerase chain reaction}

Semi-quantitative real-time PCR was performed on extracted DNA from the frozen and lyophilised luminal contents for $R$. flavefaciens, $F$ succinogenes, $S$. bovis and total bacterial load, using the MX3000P Q-PCR system (Stratagene Ltd, Cambridge, Cambs, UK). The PCR reaction contained $10 \times$ Thermo-Start ${ }^{\circledR}$ standard buffer, $25 \mathrm{mM}-\mathrm{MgCl}_{2}, 5 \mathrm{~mm}$ each dNTP, Thermo-Start ${ }^{\circledR}$ DNA polymerase (Abgene Ltd, Epsim, Surrey, UK), $300 \mathrm{~mm}$ each forward and reverse primer, $200 \mathrm{~mm}$ probe, DNA template (from frozen or lyophilised contents) and molecular biological-grade water (BDH, Poole, Dorset, UK). Thermal cycling conditions were $2 \mathrm{~min}$ at $50^{\circ} \mathrm{C}$ followed by $10 \mathrm{~min}$ at $95^{\circ} \mathrm{C}$ and forty cycles of $15 \mathrm{~s}$ at $95^{\circ} \mathrm{C}$ and $2 \mathrm{~min}$ at $60^{\circ} \mathrm{C}$. Samples were run in duplicate for each quantification assay.

Taqman ${ }^{\circledR}$ probes and oligonucleotide primers for $R$. flavefaciens, F. succinogenes and $S$. bovis were designed using Primer Express ${ }^{\circledR}$ software (PE Applied Biosystems, Warrington, Ches, UK). Probe and primer sets were designed based on $R$. flavefaciens, $F$. succinogenes and $S$. bovis 16S rDNA sequences published in GenBank ${ }^{\circledR}$. Probes and primers were 
tested for specificity using the Basic Local Alignment Search Tool (BLAST; National Center for Biotechnology Information (NCBI), Bethesda, MD, USA). A previously published universal primer and probe set was used for the determination of the total bacterial load ${ }^{(13)}$. The probes and primers were synthesised by MWG-Biotech AG (Ebersberg, Germany). All probes contained 6-carboxy-fluorescein as the $5^{\prime}$ reporter and 6-carboxy-tetramethyl-rhodamine (TAMRA) as the $3^{\prime}$ quencher. Details of primers and probes are given in Table 1.

For relative quantification of $R$. flavefaciens, F. succinogenes and $S$. bovis the comparative cycle threshold $\left(\mathrm{C}_{\mathrm{T}}\right.$; Fig. 1) method was used ${ }^{(19)}$, which involved normalisation of the number of target copies to total bacterial load (universal). The $\Delta \mathrm{C}_{\mathrm{T}}$ was first calculated (universal mean $\mathrm{C}_{\mathrm{T}}$ - specific bacteria mean $\mathrm{C}_{\mathrm{T}}$ ). The normalised level of abundance was calculated using the formula $=1 \cdot 78^{-\Delta \mathrm{CT}}$, where 1.78 was derived from Nadkarni et al. ${ }^{(13)}$ as the response to standard amounts of DNA obtained with the universal primer and probe set. As the target bacteria were generally represented in small proportions relative to total bacterial load, data were transformed by multiplying by 1000 to allow for ease of data handling. Validation studies were carried out to demonstrate that the amplification efficiencies of the universal primers and probe set and specific bacteria were equivalent. This involved generating relative standard curves for each primer and probe set using serial dilutions of purified DNA. The $\Delta \mathrm{C}_{\mathrm{T}}(y)$ between the universal set and each specific bacterium was plotted $v . \log$ (dilution; $x$ ) to calculate the slope of the line (by linear regression analyses). Slopes for $R$. flavefaciens, $F$. succinogenes and $S$. bovis were all $<0 \cdot 1$ as required (Fig. 2).

\section{Statistical analyses}

Data generated from real-time PCR were not normally distributed; a logarithmic (base 10) transformation was therefore performed on all of the data before statistical analysis. Values for the relative amounts of bacteria in the various regions of the hindgut were analysed for significant differences using two-way ANOVA in GenStat ${ }^{\circledR}$ release 9.1 (Lawes Agricultural Trust, Harpenden, Herts, UK). This was done separately for both the frozen and lyophilised material. Values for bacterial species and preservation treatment (frozen or lyophilised) were also analysed for significant differences using twoway ANOVA. Comparisons between treatment groups were made by least significant difference equations. $P$ values of $<0.05$ were considered statistically significant.

\section{Results}

The quantification of $R$. flavefaciens, $F$. succinogenes and $S$. bovis, involving the normalisation of the number of target copies to total bacterial load, confirmed the application of real-time PCR to successfully detect $R$. flavefaciens, $F$. succinogenes and $S$. bovis from the equine hindgut (Fig. 1). The relative quantification of $R$. flavefaciens, $F$. succinogenes and $S$. bovis $16 \mathrm{~S}$ rDNA extracted from the large intestine of fourteen healthy horses confirmed that these bacterial species are all abundant at detectable levels throughout the equine hindgut, differing in relative quantification from region to region. 


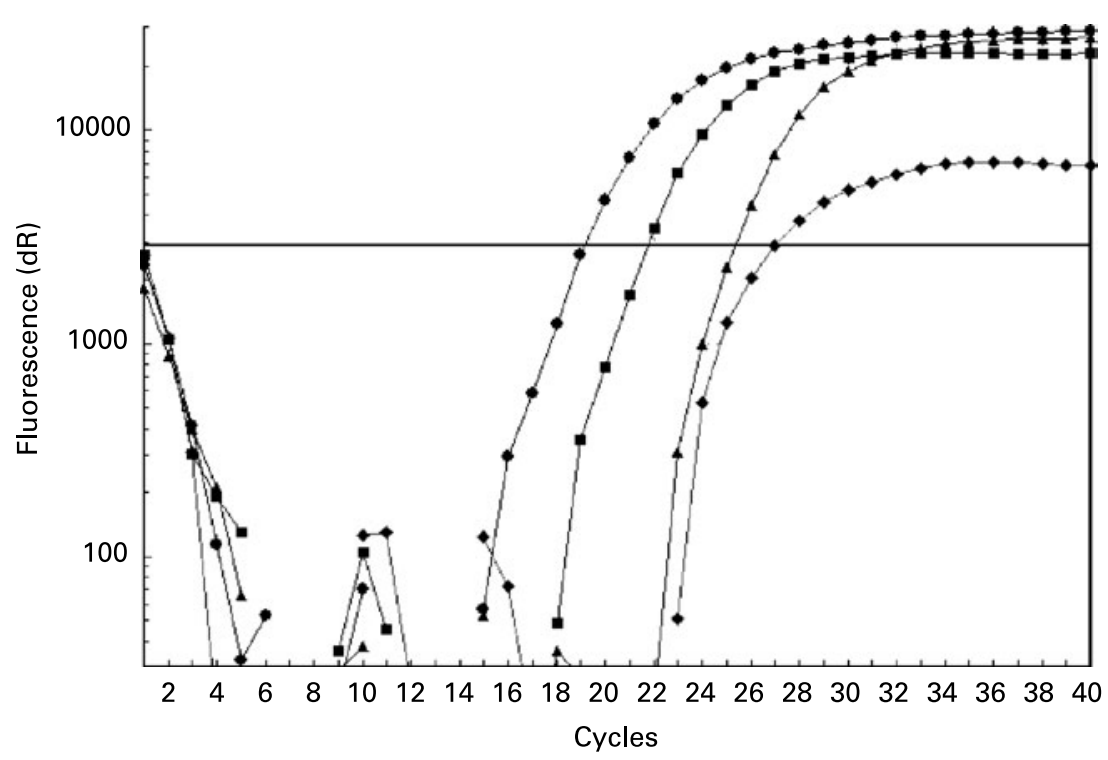

Fig. 1. A typical example of amplification plots obtained during the real-time PCR reaction for the universal (- - -), Ruminococcus flavefaciens (-口-), Fibrobacter succinogenes $(-\boldsymbol{\Delta}-)$ and Streptococcus bovis $(--)$ primer and probe sets. The horizontal line represents the threshold fluorescence and corresponds to the cycle threshold value for a given sample. $\mathrm{dR}$, baseline-subtracted fluorescence.

Analysis of real-time data showed no significant interaction between bacterial species and hindgut region; therefore, main effects were examined in isolation. Data derived from real-time PCR revealed that region of the equine hindgut significantly affected the overall bacterial load of $R$. flavefaciens, $F$. succinogenes and $S$. bovis in both frozen $(P=0.011$; Table 2$)$ and lyophilised $(P<0.001$; Table 3) luminal contents. Overall, caecal samples had significantly $(P<0.01)$ fewer $R$. flavefaciens, $F$. succinogenes and $S$. bovis than were present in the luminal contents of the ventral colon, dorsal colon and rectum in both the frozen and lyophilised samples. However, similar candidate bacterial loads were observed between the luminal contents of ventral colon, dorsal colon and rectum in the frozen samples (Table 2). In contrast, in the lyophilised samples significantly fewer $R$. flavefaciens, $F$. succinogenes and $S$. bovis were present in the luminal contents of the ventral colon $(P<0.05$; Table 3), compared with the dorsal colon and rectum, which were similar.

With respect to the three individual bacteria, $R$. flavefaciens was the predominant bacterial species within each region of the equine hindgut sampled, for both the frozen and lyophilised material, and overall was present in significantly greater amounts than both $F$. succinogenes $(P<0.05)$ and $S$. bovis $(P<0.01)$ (Tables 2 and 3). However, in the frozen samples values for $F$. succinogenes and $S$. bovis were similar (Table 2), whilst in the lyophilised samples $F$. succinogenes was present at significantly $(P<0.05)$ higher levels than $S$. bovis throughout each region of the hindgut (Table 3 ).

Further analysis of real-time data revealed a significant $(P<0.001)$ interaction between bacterial species and preservation treatment (Table 4). Values for $R$. flavefaciens and $F$. succinogenes were significantly $(P<0 \cdot 05)$ higher in the lyophilised material compared with the frozen samples, whereas similar values were obtained for $S$. bovis in both the frozen and lyophilised material.

\section{Discussion}

The successful quantification of specific candidate bacteria involving the normalisation of the number of target copies to total bacterial load confirmed the efficacy of real-time PCR to successfully detect these bacteria within the equine hindgut. Semi-quantitative analysis of $R$. flavefaciens, $F$. succinogenes and $S$. bovis required specific probe and primer sets that were designed to target $16 \mathrm{~S}$ rDNA using published sequences from bacterial strains that had already been identified in the equine ${ }^{(14,20)}$. In addition to these specific bacterial sets, a universal probe and primer set was also utilised that had a broad inter-species specificity capable of detecting as many of the bacterial populations within the equine hindgut as possible. However, modern molecular techniques such as real-time PCR have been used in only a limited number of studies, with few papers focusing on the whole equine bacterial community ${ }^{(11,15)}$; consequently, there are no equine-specific universal primer and probe sets. Therefore, the universal set used for the present study was a previously published set that had been designed to specifically detect the major groups of bacteria, as listed by Bergey's Manual of Determinative Bacteriology ${ }^{(13)}$. It is possible, however, that certain groups of equine-specific bacteria may not have been detected and/or efficiently amplified by this universal set. A high degree of genetic diversity has been reported for the bacterial community present in the equine hindgut ${ }^{(11,18)}$, with novel clusters identified; these included clusters that were only represented by equine sequences and as such may be regarded as equine-only groups. However, there is also a great deal of microbiological diversity within the gastrointestinal tract in other species, and previous studies have already established the use of the universal primer and probe set to monitor bacterial load in gut contents ${ }^{(17)}$. Further molecular research using several primer sets would be required for an exhaustive survey of the microbial diversity from which an 
(A)

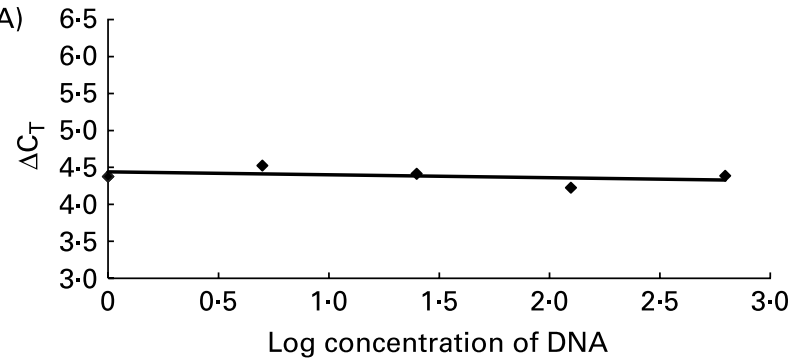

(B) 6.5

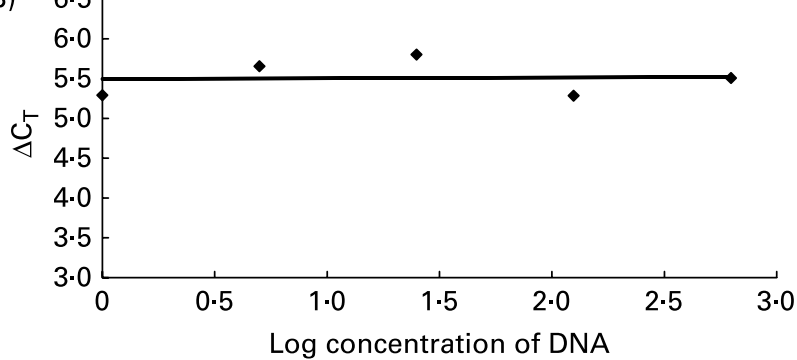

(C)

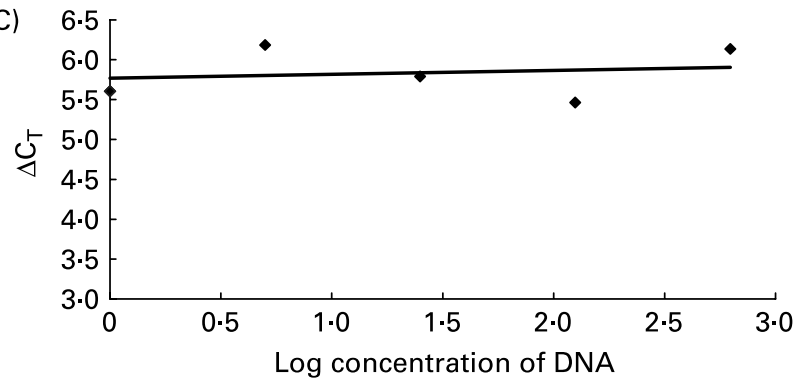

Fig. 2. Validation studies demonstrating the amplification efficiencies of the universal primer and probe set to those of Ruminococcus flavefaciens $(A ; y=-0.0401 x)$, Fibrobacter succinogenes $(B ; y=0.0093 x)$ and Streptococcus bovis $(C ; y=0.0486 x)$. The slope of each line was calculated by linear regression analysis. The absolute value of the slope was close to zero $(y=<0 \cdot 1)$, therefore the efficiencies of the target and reference genes were similar. $\mathrm{C}_{\mathrm{T}}$, cycle threshold. equine-specific universal probe and primer set could be designed. Nevertheless, the data reported here are semiquantitative and for the first time compare $R$. flavefaciens, $F$. succinogenes and $S$. bovis relative to the total bacterial load throughout the various regions of the equine hindgut.

From the early hybridisation studies investigating the equine hindgut, some authors ${ }^{(14)}$ have lyophilised the material in order to account for the DM increase along the intestinal tract. However, there is no information available in the literature on the effect of preservation method on data obtained from studies using PCR methodologies. One of the aims within the present study was to investigate the possible implications of lyophilising material before extracting the DNA. A very important finding in the present study was that significantly higher values were obtained for $R$. flavefaciens and $F$. succinogenes in the lyophilised material compared with the non-lyophilised samples, with no differences detected between preservation methods for $S$. bovis. It is unclear why these differences occurred; however, they may be attributed to differences in the liquid- and solid-associated bacteria. For instance, higher fibrolytic activities have been reported in the solid-associated bacteria in the equine hindgut ${ }^{(21)}$. In addition, freezing per se is unlikely to explain the differences observed, as the freezing occurs in both methods of preservation. Rather, it is possible that differences in preservation method may also be attributable to enzymic degradation of DNA, which may be released from lysed cells during subsequent thawing of frozen material before sub-sampling. Consequently, the preservation method of samples appears to be an important consideration in the enumeration of bacteria using this methodology as this could potentially have implications for quantifying and comparing results obtained within and across studies. It is also important to note that data from frozen samples in the present study were comparable with previous reports in the literature ${ }^{(14)}$, whilst the abundance of the three candidate bacteria determined from lyophilised material were markedly higher than previous reports.

Table 2. Semi-quantitative levels of Ruminococcus flavefaciens, Fibrobacter succinogenes and Streptococcus bovis in frozen luminal contents of the equine caecum, ventral colon, dorsal colon and rectum $(n 14)^{\star}$

\begin{tabular}{|c|c|c|c|c|c|c|c|c|c|}
\hline & \multicolumn{6}{|c|}{ Bacterial species } & & & \\
\hline & \multicolumn{2}{|c|}{ R. flavefaciens } & \multicolumn{2}{|c|}{ F. succinogenes } & \multicolumn{2}{|c|}{ S. bovis } & \multicolumn{2}{|c|}{ Region mean } & $P$ \\
\hline \multicolumn{10}{|l|}{ Hindgut region } \\
\hline Caecum & $1 \cdot 767$ & $5 \cdot 85$ & 1.529 & $3 \cdot 38$ & 1.426 & 2.67 & $1 \cdot 574^{\mathrm{a}}$ & $3 \cdot 75$ & \\
\hline Dorsal colon & 1.891 & $7 \cdot 78$ & 1.676 & $4 \cdot 74$ & $1 \cdot 745$ & $5 \cdot 60$ & $1 \cdot 771^{\mathrm{b}}$ & $5 \cdot 90$ & \\
\hline Rectum & 1.969 & $9 \cdot 31$ & 1.743 & $5 \cdot 53$ & 1.837 & $6 \cdot 87$ & $1 \cdot 850^{\mathrm{b}}$ & $7 \cdot 08$ & \\
\hline Bacteria mean & $1.903^{\mathrm{d}}$ & 8.00 & $1.694^{\mathrm{C}}$ & 4.94 & $1.689^{c}$ & 4.89 & & & \\
\hline Bacteria mean SED & 0.0822 & & & & & & & & 0.013 \\
\hline Region mean SED & 0.0949 & & & & & & & & 0.011 \\
\hline Bacteria $\times$ region mean SED & 0.1644 & & & & & & & & NS \\
\hline
\end{tabular}

SED, Standard error of the difference, CT, cycle threshold.

${ }_{\mathrm{a}, \mathrm{b}}$ Mean values within a column with unlike superscript letters were significantly different $(P<0.05)$.

$c, \mathrm{~d}$ Mean values within a row with unlike superscript letters were significantly different $(P<0.05)$

* Data (log-transformed) are expressed relative to mean total bacterial load. Actual percentages of total bacterial load are also shown. Log-transformed data were derived according to the formula $=\log _{10}\left(1000\left(1 \cdot 78^{-\Delta C T}\right)\right)$. 
Table 3. Semi-quantitative levels of Ruminococcus flavefaciens, Fibrobacter succinogenes and Streptococcus bovis in lyophilised luminal contents of the equine caecum, ventral colon, dorsal colon and rectum $(n 14)^{\star}$

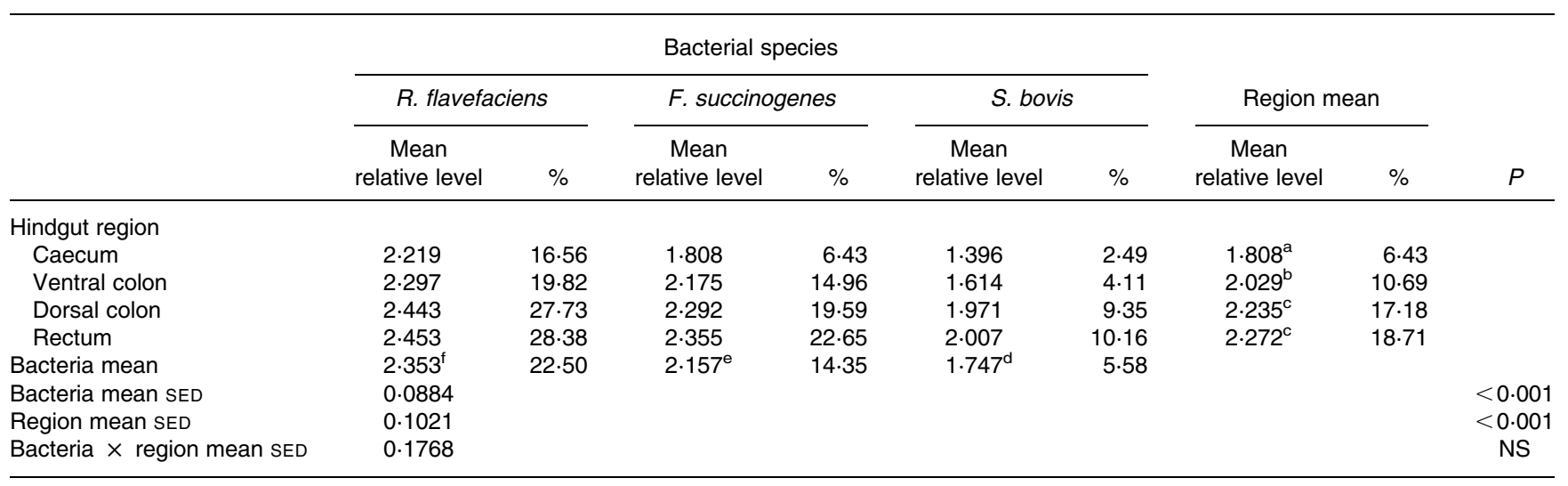

SED, Standard error of the difference, CT, cycle threshold.

$\mathrm{a}, \mathrm{b}, \mathrm{c}$ Mean values within a column with unlike superscript letters were significantly different $(P<0.05)$

$\mathrm{d}, \mathrm{e}, \mathrm{f}$ Mean values within a row with unlike superscript letters were significantly different $(P<0.05)$.

* Data (log-transformed) are expressed relative to mean total bacterial load. Actual percentages of total bacterial load are also shown. Log-transformed data were derived according to the formula $=\log _{10}\left(1000\left(1 \cdot 78^{-\Delta C T}\right)\right)$.

Real-time PCR data revealed frozen caecal contents had lower levels of the three candidate bacteria compared with the contents obtained from the ventral colon, dorsal colon and rectum. This is comparable with earlier observations established in culture-based experiments whereby a lower concentration of total anaerobic bacteria has been detected in the caecum $^{(22)}$. Previous molecular analysis of caecal contents suggests $R$. flavefaciens to be the predominant cellulolytic bacterial species in the equine caecum, with lower abundance reported for $F$. succinogenes ${ }^{(14)}$. This concurs with the findings of the present study whereby the relative abundance of $R$. flavefaciens was notably higher than $F$. succinogenes in all regions of the large intestine in both the frozen and lyophilised material. However, the relative abundance reported for $R$. flavefaciens in the frozen caecal samples in the present study $(5.85 \%)$ is lower than the $9 \%$ reported by Julliand et al. ${ }^{(14)}$. Daly also detected $R$. flavefaciens in the various regions of the equine hindgut, but did not recover any sequences relating to $F$. succinogenes ${ }^{(11)}$, whilst $\operatorname{Lin} \&$
Stahl $^{(23)}$ concluded that $F$. succinogenes accounted for $12 \%$ of total rRNA extracted from the caecum, which contrasts with the 3.38 and $6.43 \%$ reported for frozen and lyophilised caecal samples, respectively, in the present study. Nevertheless, differing methodologies employed in the various studies may explain these conflicting results as well as differences in the host animal diet. Interestingly, DNA extracted from $F$. succinogenes has been shown to amplify less efficiently than other gut bacteria ${ }^{(16)}$; furthermore, diet has also been shown to play a major role in the biodiversity of microbial populations in the equine hindgut, with $F$. succinogenes appearing to thrive on low-quality roughage, unlike that of many other cellulolytic bacteria ${ }^{(24)}$. Moreover, the levels reported by Lin \& Stahl ${ }^{(23)}$ were from a single animal, while Julliand et al. ${ }^{(14)}$ reported a marked inter-animal variation in the percentage of $F$. succinogenes present in the caecum of horses fed identical diets. However, a limitation of the present study was that the nutritional history of the horses was unavailable.

Table 4. Semi-quantitative levels of Ruminococcus flavefaciens, Fibrobacter succinogenes and Streptococcus bovis in lyophilised and frozen luminal contents of the equine hindgut $(n 14)^{\star}$

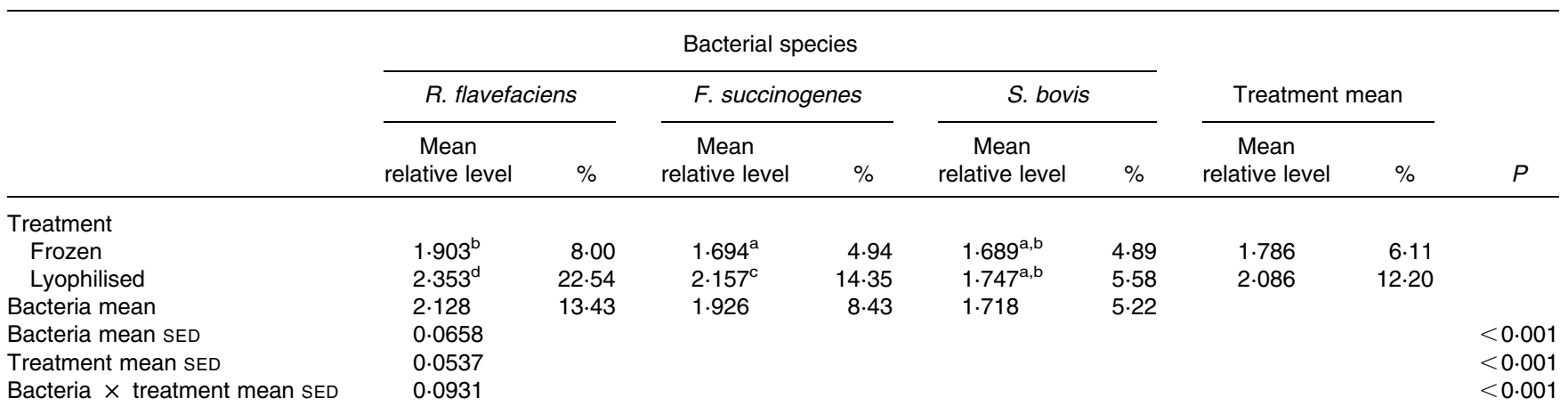

SED, Standard error of the difference, CT, cycle threshold.

a,b,c,d Mean values within a row or column with unlike superscript letters were significantly different $(P<0.05)$.

* Data (log-transformed) are expressed relative to mean total bacterial load. Actual percentages of total bacterial load are also shown. Log-transformed data were derived according to the formula $=\log _{10}\left(1000\left(1 \cdot 78^{-\Delta C T}\right)\right)$. 
One of the novel findings presented in the present study was the determination of the main lactic acid bacteria, S. bovis. To the best of our knowledge the abundance of this bacteria has yet to be determined within the equine hindgut, although several cultivation studies have focused on the lactobacilli and streptococci bacterial groups as a whole ${ }^{(22,25)}$. Real-time PCR data revealed $S$. bovis to be present in lower amounts in the caecum compared with the ventral colon, dorsal colon and rectum in both the frozen and lyophilised material. This concurs with the findings of culture-based experiments, whereby, on average, the concentration of lactobacilli and streptococci tends to be lower in the caecum than the colon, which has been attributed to the faster rate of passage of soluble carbohydrate and undigested starch through the caecum compared with the colon ${ }^{(22)}$.

Although $S$. bovis is a normal inhabitant of the gastrointestinal tract of the horse ${ }^{(26)}$ it has been implicated as a putative causative agent for equine hindgut acidosis and related conditions, such as laminitis ${ }^{(18)}$. These conditions often arise as a result of dietary changes that lead to the proliferation of $S$. bovis and the production of excessive levels of lactic acid in the hindgut. S. bovis ferments non-structural carbohydrates and produces lactate as its main fermentation endproduct during rapid multiplication, eventually leading to decreases in hindgut $\mathrm{pH}$. Consequently, diets high in non-structural carbohydrates can be detrimental to the maintenance of a homeostatic hindgut environment ${ }^{(3)}$, and in severe cases this can lead to the death of the animal. The present paper has highlighted the potential uses of modern molecular technologies in exploring the role of $S$. bovis in equine gastrointestinal disease. Since 1952, S. bovis has been studied more extensively than any other lactic acid-producing bacteria of ruminal origin, with numerous strains having been isolated from cattle and sheep, characterised on both morphological and biochemical characteristics ${ }^{(27,28)}$. However, various strains have been identified that do not cause disease ${ }^{(20)}$. As such, cultivation methods cannot be used as a reliable way to detect rising levels of $S$. bovis as the cause of gastrointestinal disease. More recently, $S$. bovis has been characterised on a molecular level in other species, using similar techniques to those presented here ${ }^{(29,30)}$. However, to date this is the only study that has determined the abundance of $S$. bovis in equine hindgut contents. Nevertheless, further studies are required in equines to investigate the role that $S$. bovis plays in fermentative acidosis, gastric ulceration and laminitis. Furthermore, studies also need to consider other lactate-producing bacteria, since $S$. bovis is unlikely to be the sole bacterial species involved in gastrointestinal disease.

By establishing a model of hindgut function using noninvasive techniques, further research can explore the role of $S$. bovis, and other key bacteria, in different stages of gastrointestinal disease, and not just at the terminal stages following euthanasia. Data from both the frozen and lyophilised samples showed similar levels of $R$. flavefaciens, $F$. succinogenes and $S$. bovis relative to total bacterial load in luminal contents obtained from the dorsal colon and rectum. These findings indicate that, similar to other single-stomached animals $^{(20)}$, equine faecal material could reflect the microbiological characteristics of the distal colon. This would subsequently allow faeces to act as a model for the distal colon, facilitating accurate determination of changes in gut microflora without the need for surgically modified animals or the use of slaughter material, which allows for no information on the animal's health or dietary management. Furthermore, data from the frozen luminal contents indicated similarities between the three bacteria in the ventral colon, dorsal colon and rectum, potentially allowing faeces to be used as a model for the whole colon. However, more work is required to further develop real-time Q-PCR for quantification of a greater number of candidate bacterial species, in particular key fibrolytic species and lactate-producing bacteria (especially from the genus Streptococcus), and to assess the effect of environmental factors, such as diet, on the relationship between faecal and colonic bacterial populations. If a conclusive link can be established in healthy horses using faecal material to give an indication of bacterial community structure, then faecal material could potentially become a non-invasive tool to accurately monitor changes in the colonic bacterial populations in response to diet and other environmental factors, and allow for the accurate measurement of potential disease-causing bacteria, such as strains of $S$. bovis (and other bacteria) in the colon. In human subjects, reports have suggested a potential relationship between increased faecal carrier levels of $S$. bovis and human gastrointestinal disease ${ }^{(31-33)}$. If a similar trend can be established in the equine, faecal material has the potential to be employed as a model for identifying and monitoring the level of $S$. bovis in the hindgut, thus detecting rising levels or imbalances at the early stages of disease when treatment can be more effective.

\section{Acknowledgements}

The authors are grateful to Cheshire Equine Services for providing hindgut luminal contents. The present study was funded by the Royal (Dick) School of Veterinary Studies, University of Edinburgh. The authors have no conflicts of interest that affect the content or publication of this paper. P. M. H. designed, optimised and validated the real-time PCR assays, K. M. was a University of Edinburgh postgraduate student who carried out aspects of the study, whilst J. M. D. M. secured funding for this research and was responsible for completing some of the real-time PCR assays.

\section{References}

1. Hainze MTM, Muntifering RB \& McCall CA (2003) Fibre digestion in horses fed typical diets with and without exogenous fibrolytic enzymes. J Equine Vet Sci 23, 111-115.

2. Glinsky MJ, Smith RM, Spires HR \& Davis L (1976) Measurement of volatile fatty acid production rates in the caecum of the pony. J Anim Sci 42, 1465-1470.

3. McLean BML, Hyslop JJ, Longland AC, Cuddeford D \& Hollands T (2000) Physical processing of barley and its effects on intra-caecal fermentation parameters in ponies. Anim Feed Sci Technol 85, 79-87.

4. Carroll CL, Hazard G, Coloe PJ \& Hooper PT (1987) Laminitis and possible enterotoxaemia associated with carbohydrate overload in mares. Equine Vet $J$ 19, 344-346.

5. Clarke LL, Roberts MC \& Argenzio RA (1990) Feeding and digestive problems in horses: physiologic responses to a concentrate meal. Vet Clin N Am Equine 6, 433-451. 
6. Garner HE, Hutcheson DP, Coffman JR \& Hahn AW (1977) Lactic acidosis: a factor associated with equine laminitis. J Anim Sci 45, 1037-1041.

7. Rowe JB, Lees MJ \& Pethick DW (1994) Prevention of acidosis and laminitis associated with grain feeding in horses. $J$ Nutr 124, 2742S-2744S.

8. Tajima K, Aminov RI, Nagamine T, Ogata K, Nakamura M, Matsui H \& Benno Y (1999) Rumen bacterial diversity as determined by sequence analysis of $16 \mathrm{~S}$ rDNA libraries. FEMS Microbiol Ecol 29, 159-169.

9. Wilson KH \& Blitchington RB (1996) Human colonic biota studied by ribosomal DNA sequence analysis. Appl Environ Microbiol 62, 2273-2278.

10. Pryde SE, Richardson AJ, Stewart CS \& Flint HJ (1999) Molecular analysis of the microbial diversity present in the colonic wall, colonic lumen and caecal lumen of a pig. Appl Environ Microbiol 65, 5372-5377.

11. Daly K, Stewart CS, Flint HJ, Soraya P \& Shirazi-Beechey SP (2001) Bacterial diversity within the equine large intestine as revealed by molecular analysis of cloned 16S rRNA genes. FEMS Microbiol Ecol 38, 141-151.

12. Halliwell REW, Fleischman JB, Mackay-Smith M, Beech J \& Gunson DE (1979) The role of allergy in chronic pulmonary disease of horses. J Am Vet Med Assoc 174, 277-281.

13. Nadkarni MA, Martin FE, Jacques NA \& Hunter N (2002) Determination of bacterial load by real-time PCR using a broad-range (universal) probe and primers set. Microbiology 148, 257-266.

14. Julliand V, de Vaux A, Millet L \& Fonty G (1999) Identification of Ruminococcus flavefaciens as the predominant cellulolytic bacterial species of the equine cecum. Appl Environ Microbiol 65, 3738-3741.

15. Daly K, Soraya P \& Shirazi-Beechey SP (2003) Design and evaluation of group-specific oligonucleotide probes for quantitative analysis of intestinal ecosystems: their application to assessment of equine colonic microflora. FEMS Microbiol Ecol 44, 243-252.

16. Tajima K, Aminov RI, Nagamine T, Matsui H, Nakamura M \& Benno Y (2001) Diet-dependent shifts in the bacterial population of the rumen revealed with real-time PCR. Appl Environ Microbiol 67, 2766-2774.

17. Haarman M \& Knol J (2005) Quantitative real-time PCR assays to identify and quantify fecal Bifidobacterium species in infants receiving a prebiotic infant formula. Appl Environ Microbiol 71, $2318-2324$.

18. Milinovich GJ, Trott DJ, Burrell AW, Thoefner MB, Blackall LL, Al Jassim RAM, Morton JM \& Pollitt CC (2006) Changes in equine hindgut bacterial population during oligofructoseinduced laminitis. Environ Microbiol 8, 885-898.
19. Applied Biosystems (2001) User Bulletin 2: Relative Quantitation of Gene Expression, pp. 1-36. Warrington: Applied Biosystems.

20. Whitehead TR \& Cotta MA (1993) Development of a DNA probe for Streptococcus bovis by using a cloned amylase gene. J Clin Microbiol 31, 2387-2391.

21. Michalet-Doreau B, Fernandez I, Peyron C \& Millet L (2001) Fibrolytic activities and cellulolytic bacterial community structure in solid and liquid phases of rumen contents. Reprod Nutr Dev 41, 187-194.

22. de Fombelle A, Julliand V, Drogoul C \& Jacotot E (2001) Feeding and microbial disorders in horses: 1 - Effects of an abrupt incorporation of two levels of barley in a hay diet on microbial profile and activities. J Equine Vet Sci 21, 439-445.

23. Lin CZ \& Stahl DA (1995) Taxon-specific probes for the cellulolytic genus Fibrobacter reveal abundant and novel equineassociated populations. Appl Environ Microbiol 61, 1348-1352.

24. Koike S, Shingu Y, Inaba H, Kawai M, Kobayashi Y, Hata H, Tanaka K \& Okubo M (2000) Faecal bacteria in Hokkaido native horses as characterised by microscopic enumeration and competitive polymerase chain reaction assays. J Anim Eq Sci 11, 45-50.

25. de Fombelle A, Varloud M, Goachet AG, Jacotot E, Philippeau C, Drogoul C \& Julliand V (2003) Characterisation of the microbial and biochemical profile of different segments of the digestive tract in horses given two distinct diets. Anim Sci 77, 293-304.

26. Al Jassim RAM \& Rowe JB (1999) A better understanding of acidosis and its control. Rec Adv Anim Nutr Aust 12, 91-96.

27. Russell JB \& Robinson PH (1984) Composition and characteristics of strains of Streptococcus bovis. J Dairy Sci 67, $1525-1531$.

28. Cotta MA (1988) Amylolytic activity of selected species of ruminal bacteria. Appl Environ Microbiol 54, 772-776.

29. Whitehead TR \& Cotta MA (2000) Development of molecular methods for identification of Streptococcus bovis from human and ruminal origins. FEMS Microbiol Lett 182, 237-240.

30. Al Jassim RAM, Scott PT, Trebbin AL, Trott D \& Pollitt CC (2005) The genetic diversity of lactic acid producing bacteria in the equine gastrointestinal tract. FEMS Microbiol Lett 248, $75-81$.

31. Dubrow RS, Edberg S, Wikfors E, Callan D, Troncalle F, Vender R, Brand M \& Yapp R (1991) Faecal carriage of Streptococcus bovis and colorectal adenomas. Gastroenterology 101, $721-725$

32. Awada A, Van der Auwera P, Meunier F, Daneau D \& Klastersky J (1992) Streptococcal and enterococcal bacterium in patients with cancer. Clin Infect Dis 15, 33-48.

33. Harley W (1992) Streptococcus bovis meningitis associated with colonic cillous adenoma. Clin Infect Dis 14, 979-980. 